Article title: Distance Teacher Training in Periods of Emergency (Covid-19 Pandemic)

Authors: Panagiotes Anastasiades[1], Konstantinos Kotsidis[2], Christos Synnefakis[3], Alexia Spanoudaki[4]

Affiliations: E-learning Lab, University of Crete, University Campus of Gallos, Rethymno, Greece[1]

Orcid ids: 0000-0002-1347-2176[1], 0000-0002-4483-060X[2], 0000-0003-3304-7027[3], 0000-0002-5369-518X[4]

Contact e-mail: kkotsidis@edc.uoc.gr

License information: This work has been published open access under Creative Commons Attribution License http://creativecommons.org/licenses/by/4.0/, which permits unrestricted use, distribution, and reproduction in any medium, provided the original work is properly cited. Conditions, terms of use and publishing policy can be found at https://www.scienceopen.com/.

Preprint statement: This article is a preprint and has not been peer-reviewed, under consideration and submitted to UnisaRxiv for open peer review.

DOI: 10.25159/UnisaRxiv/000005.v1

Preprint first posted online: 31 May 2021

Keywords: teacher training, school distance education, Covid-19 


\section{Distance Teacher Training in Periods of Emergency (Covid-19 Pandemic)}

\author{
Panagiotes Anastasiades \\ https://orcid.org/0000-0002-1347-2176 \\ University of Crete, Greece
}

\section{Christos Synnefakis}

https://orcid.org/0000-0003-3304-7027

University of Crete, Greece

\author{
Konstantinos Kotsidis \\ https://orcid.org/0000-0002-4483-060X \\ University of Crete, Greece \\ kotsidis@edc.uoc.gr
}

Alexia Spanoudaki
https://orcid.org/0000-0002-5369-518X
University of Crete, Greece

\section{Abstract}

The closing of schools at the beginning of spring 2020 in Greece highlighted the need for school distance education to make up for lost teaching time and to maintain learners' contact with the educational process and other members of the school community. However, the teachers needed support in this urgent situation since they did not have previous experience in school distance education. The Laboratory for Advanced Teaching Technologies for Lifelong Learning and Distance Education (E-Learning Lab) of the University of Crete, attempted to contribute with its own means to the support of these teachers. Within this framework, fast-pace, distance seminars were designed and implemented to support teachers on pedagogical issues of distance education. A total of 20 distance training seminars were conducted from 19 March to 29 April 2020 in which more than 40000 teachers of primary and secondary education in Greece participated. The overall presentation and assessment of the training actions showed not only the enormous interest of the teaching community but also the need for such training actions with particular emphasis on the principles and the methodology of school distance education, synchronous and asynchronous learning environments, and the designing or planning of teaching scenarios based on the pedagogical approaches compatible with distance learning.

Keywords: teacher training, school distance education, Covid-19

\section{Introduction}

Supporting the teachers with key issues regarding distance education (DE) became a major priority during the first lockdown, as the teachers had no previous experience in school distance education (SDE).

The Department of Primary Education of the University of Crete and more specifically the Laboratory for Advanced Teaching Technologies for Lifelong Learning and 
Distance Education (E-Learning Lab) responded to the need for teacher support, and designed and implemented fast-paced, free distance learning programmes for primary and secondary education teachers.

The purpose of this paper is on the one hand to summarise the training activities that took place in the first period of the lockdown in the direction of introductory training of teachers on issues related to SDE, and on the other hand to investigate the teachers' attitudes to participation in training.

The structure of the paper is as follows: In the first section, the issues of the implementation of the SDE in an emergency situation, such as Covid-19, are explored. The second section summarises the contribution of the University of Crete and the ELearning Lab to the support and training of teachers in introductory issues related to SDE focusing on the pedagogical dimension of the whole project. In the third section, a comprehensive assessment of the training activities during the first period of the lockdown (March to April 2020) is done. The paper is completed with the conclusions section.

\section{School Distance Education in Periods of Emergency (Covid-19 Pandemic)}

The term "school distance education" refers to the provision of education for primary and secondary education, which is provided remotely, focuses on school-age individuals, and is autonomous and complementary (Vergou, Koutsoumpa, and Mouzakis 2016, 26).

During the first period of the Covid-19 pandemic, 80 per cent of the global student population was affected by restrictive measures in 138 countries of which the impact has not yet been studied (Flores and Gago 2020, 510). The need to deal with the negative impact of the suspension of the educational process pushed the shift to distance learning not as an option but as a coercive de facto enforcement (Toquero 2020, 171).

The emphasis in this first period of the pandemic was therefore placed on (Anastasiades 2020):

- ensuring access to the Panhellenic School Network services, technological tools and infrastructure; and

- reconnecting students with classmates and teachers in an educational environment of technological mediation.

The response of the teaching community exceeded all expectations as it managed to significantly restore a first contact with the students, despite the technological problems and that teachers lacked the training. Obviously, the indiscriminate transfer of the philosophy of face-to-face teaching methods and techniques into purely technological 
or technocentric terms in DE environments created risks of regarding DE as a problematic choice.

The absence of the minimum pedagogical conditions for the basic implementation of SDE was more than obvious. It was therefore necessary to try and support teachers on the basis of pedagogical approaches based on the fundamental principles of DE, such as the interaction between learners, learners with teachers and learners with educational materials, practice communities, and the three dimensions of the exploration community model (social, teaching and cognitive presence) (Garrison, Anderson, and Archer 2001, 14-15). These principles helped to design and implement distance learning school activities with an emphasis on social interaction (Anastasiades 2018, 603).

\section{Case Study Description}

The E-Learning Lab of the Department of Primary Education of the University of Crete responded to the need to support primary and secondary education teachers in their efforts to implement introductory activities of DE with their students, in the period of March to April 2020, by designing and implementing fast-paced seminars with the method of DE.

\section{Objective}

The objective of the training actions is divided into three thematic units:

- Fundamental principles of DE: Basic theories, differences between DE and inperson teaching, the importance of educational material, social dimension.

- The pedagogical utilisation of ICT in an SDE environment (synchronous, asynchronous environments and blended learning environments).

- Design of educational material: Introductory activities for the critical utilisation of the existing material with the methodology of DE or development of scenarios of teaching intervention based on the methodology of DE.

\section{Target Group}

The target group of the programme was composed of primary and secondary school teachers.

\section{Implementation Methodology}

Each training seminar lasted six hours and was structured on two levels as discussed below. 
Synchronous School Distance Education (3 hours)

Each training seminar provided one training meeting, in which interested parties could participate via

- videoconferencing for a limited number of participants (150), or

- real-time streaming (live-streaming) for an unlimited number of participants.

For the most effective coverage of the needs of practice and the thorough support of the trainees, two tutors was chosen. The first tutor focused on the synchronous e-learning environment (teleconferencing), presented the activities and interacted with the participants in the teleconference. The second tutor focused on social networks and interacted with the users who watched the live broadcast of the seminar. He received their questions and transferred them to the video conference room, giving answers via the chat option while helping and coordinating the training activity.

\section{Synchronous Distance Education (3 hours)}

The seminars were complemented with interactive educational material, specially designed with the method of DE, which the trainees had the opportunity to study asynchronously in the space and time of their choice. Finally, in the context of the training, the trainees were asked to do an optional task related to the creation of a teaching scenario using the methodology of DE. This was done to establish a direct connection between theory and practice in the context of sharing good practices.

\section{Implementation of Training Seminars}

In the context of the foregoing, the following were carried out from March to April 2020:

- 20 teleconferences with the participation of 1560 trainees; and

- 6 live-streaming sessions with 15000 participants in the "main hall" and another 25000 participants from notifications from a total of 175000 unique viewers.

The website with the educational material (www.edivea.org) was visited by over 60000 unique visitors.

\section{Research Methodology}

\section{Purpose}

The purpose of this research was to explore the views of trainee teachers regarding their impressions of their participation in this training programme. 


\section{Research Question}

How satisfied are the participants with their participation in the training seminar in terms of the trainers?

\section{Methodological Framework}

The survey was conducted in March and April 2020. It was an action survey that was synchronous, field-based and quantitative. A questionnaire was used as a means of data collection, which included closed-ended questions.

\section{Sample}

The sample of the research consisted of the 4239 teachers of different specialties (see Table 1).

Table 1: Participants via teleconferencing and live-streaming

\begin{tabular}{|l|l|l|l|l|l|l|}
\hline Gender & $\begin{array}{l}\text { Participants } \\
\text { via live- } \\
\text { streaming } \\
\boldsymbol{N}\end{array}$ & $\begin{array}{l}\text { Percentage } \\
\boldsymbol{\%}\end{array}$ & $\begin{array}{l}\text { Participants via } \\
\text { teleconferencing } \\
\boldsymbol{N}\end{array}$ & $\begin{array}{l}\text { Percentage } \\
\%\end{array}$ & Total & $\begin{array}{l}\text { Percentage } \\
\%\end{array}$ \\
\hline Male & 609 & 21.6 & 242 & 17 & 851 & 20.1 \\
\hline Female & 2209 & 78.4 & 1179 & 83 & 3388 & 79.9 \\
\hline Total & 2818 & 100 & 1421 & 100 & 4239 & 100 \\
\hline
\end{tabular}

\section{Presentation of Results}

According to the results of the research, the participants in the training seminar via teleconferencing stated that they were satisfied (4.31) with the trainers (see Table 2).

Table 2: Degree of satisfaction from the training programme of participants via teleconferencing

\begin{tabular}{|c|c|c|c|c|}
\hline \multirow{3}{*}{$\begin{array}{l}\text { How satisfied are you with your participation } \\
\text { in the training seminar regarding }\end{array}$} & \multicolumn{4}{|c|}{ Participants via teleconferencing } \\
\hline & \multicolumn{3}{|c|}{ Low level of ICT literacy } & \\
\hline & $\mathrm{n}$ & MO & SD & \\
\hline \multirow[t]{2}{*}{ the trainers } & 90 & 4.40 & 0.761 & \\
\hline & \multicolumn{3}{|c|}{ Medium level of ICT literacy } & \\
\hline \multirow[b]{2}{*}{ the trainers } & $\mathrm{N}$ & MO & SD & \\
\hline & 808 & 4.33 & 0.781 & \\
\hline \multirow{6}{*}{ the trainers } & \multicolumn{3}{|c|}{ High level of ICT literacy } & \\
\hline & $\mathrm{N}$ & MO & SD & \\
\hline & 513 & 4.26 & 0.85 & \\
\hline & \multicolumn{3}{|l|}{ Total } & \\
\hline & $\mathrm{N}$ & $\mathrm{MO}$ & SD & sig \\
\hline & 1.412 & 4.31 & 0.805 & 0.151 \\
\hline
\end{tabular}


According to the results of the research, the participants in the training seminar via livestreaming stated that they were satisfied (4.38) with the trainers (see Table 3). There were slight variations in the satisfaction level depending on the level of ICT literacy: participants with a very low ICT literacy (4.18), participants with a moderate level of ICT literacy (4.34), and participants with a high level of ICT literacy (4.46). The difference of the grade point average (GPA) is considered statistically significant $(p=0,000)$.

Table 3: Degree of satisfaction from the training programme of participants via livestreaming

\begin{tabular}{|c|c|c|c|c|}
\hline How satisfied are you with your participation & Partic & ia live & reamir & \\
\hline \multirow[b]{3}{*}{ the trainers } & \multicolumn{3}{|c|}{ Low level of ICT literacy } & \\
\hline & $\mathrm{n}$ & MO & SD & \\
\hline & 133 & 4.18 & 0.869 & \\
\hline \multirow[b]{3}{*}{ the trainers } & \multicolumn{3}{|c|}{ Medium level of ICT literacy } & \\
\hline & $\mathrm{N}$ & MO & SD & \\
\hline & 1.556 & 4.34 & 0.763 & \\
\hline \multirow{6}{*}{ the trainers } & \multicolumn{3}{|c|}{ High level of ICT literacy } & \\
\hline & $\mathrm{N}$ & MO & SD & \\
\hline & 1.128 & 4.46 & 0.720 & \\
\hline & \multicolumn{3}{|l|}{ Total } & \\
\hline & $\mathrm{N}$ & MO & SD & sig \\
\hline & 2.817 & 4.38 & 0.755 & 0.00 \\
\hline
\end{tabular}

\section{Conclusions}

The results of the concluding evaluation, based on the answers of the 4239 participants are given below.

The participants in the training seminar stated they were very satisfied with the trainers. There were slight variations in the satisfaction level depending on the level of ICT literacy: participants with very low ICT literacy (4.19), participants with a moderate level of ICT literacy (4.34), and participants with a high level of ICT literacy (4.46). The difference of the GPA is considered statistically significant $(p=0,000)$. Overall, the participants felt satisfied (4.38).

The E-Learning Lab designed and implemented 20 fast-paced seminars from 19 March to 29 April 2020, through the teleconferencing platform of Webex Meetings, while they were also broadcast live (live-streaming) on the website of the University of Crete and the E-Learning Lab and in social media (Facebook). Emphasis was placed on the principles and methodology of DE, the environments of synchronous and asynchronous $\mathrm{DE}$, and the design or formulation of teaching scenarios based on pedagogical approaches compatible with DE in order to support the teachers. 
The satisfaction of 40000 teachers of all levels for the whole training process highlighted the importance of the pedagogical approach in the design and implementation of the seminars which was based on the practical training of the trainees in both synchronous and asynchronous distance learning environments.

A key role in the design and implementation of these seminars was played by the experience accumulated by:

- the distance training of teachers (Anastasiades 2012, 243); and

- SDE through the Odysseus programme (Anastasiades 2003, 28).

\section{References}

Anastasiades, Panagiotes. 2003. "Distance Learning in Elementary Schools in Cyprus: The evaluation Methodology and Results." Computers and Education 40 (1): 17-40. https://doi.org/10.1016/S0360-1315(02)00077-5.

Anastasiades, Panagiotes. 2012. "Design of a Blended Learning Environment for the Training of Greek Teachers: Results of the Survey on Educational Needs." In Blended Learning Environments for Adults: Evaluations, edited by Panagiotes Anastasiades, 230-256. Pennsylvania: Idea. https://doi.org/10.4018/978-1-4666-0939-6.ch012.

Anastasiades, Panagiotes. 2018. "Learning and Social Network at the University of Crete [eLearning Lab].” In Exploring the Micro, Meso and Macro Navigating between Dimensions in the Digital Learning Landscape: European Distance and E-Learning Network (EDEN) Conference Proceedings, edited by A. Volungeviciene and A. Szücs, 598-605. Budapest: Eden.

Anastasiades, Panagiotes. 2020. "Distance Learning in the Era of COVID-19, Focusing on the Greek Educational System." Open Education - The Journal for Open and Distance Education and Educational Technology 16 (2): 20-48.

Flores, Maria, and Marilia Gago. 2020. "Teacher Education in Times of COVID-19 Pandemic in Portugal: National, Institutional and Pedagogical Responses." Journal of Education for Teaching 46 (4): 507-16. https://doi.org/10.1080/02607476.2020.1799709.

Garrison, Randy, Terry Anderson, and Walter Archer. 2001. "Critical Thinking, Cognitive Presence, and Computer Conferencing in Distance Education." American Journal of Distance Education 15 (1): 7-23. https://doi.org/10.1080/08923640109527071.

Toquero, Cathy Mae. 2020. "Emergency Remote Education Experiment amid COVID-19 Pandemic.” International Journal of Educational Research and Innovation 15: 162-76. https://doi.org/10.46661/ijeri.5113. 
Vergou, Maria, Maria Koutsoumpa, and Haralampos Mouzakis. 2016. "Supplementary Distance Learning for Infants: An Action Research based on Museum Education." Open Education - The Journal for Open and Distance Education and Educational Technology 12 (2): 24-39. 